\title{
Differences between Tight and Loose Cultures: A 33-Nation Study
}

Michele J. Gelfand, ${ }_{1}$ * Jana L. Raver, 2 Lisa Nishii, 3 Lisa M. Leslie, 4 lanetta Lun, 1 Beng Chong Lim, 5 Lili Duan, 6 Assaf Almaliach, 7 Soon Ang, 8 Jakobina Arnadottir, 9 Zeynep Aycan, 10 Klaus Boehnke,11 Pawel Boski,12 Rosa Cabecinhas,13 Darius Chan,14 Jagdeep Chhokar,15 Alessia D'Amato,16 Montse Ferrer,17 Iris C. Fischlmayr,18 Ronald Fischer,19 Marta Fulup, 20 James Georgas,21 Emiko S. Kashima,22 Yoshishima Kashima, 23 Kibum Kim,24 Alain Lempereur,25 Patricia Marquez,26 Rozhan Othman,27 Bert Overlaet,28 Penny Panagiotopoulou,29 Karl Peltzer, 30 Lorena R. Perez-Florizno, 31 Larisa Ponomarenko,32 Anu Realo, 33 Vidar Schei, 34 Manfred Schmitt, 35 Peter B. Smith,36 Nazar Soomro,37 Erna Szabo,18 Nalinee Taveesin,38 Midori Toyama, 39 Evert Van de Vliert,40 Naharika Vohra,41 Colleen Ward,42 Susumu Yamaguchi 43

iUniversity of Maryland. ${ }^{2}$ Queen's School of Business, Canada. ${ }^{3}$ Cornell University. ${ }^{4}$ University of Minnesota. ${ }^{5}$ Singapore and Nanyang Business School. ${ }^{6}$ McKinsey \& Company, Washington, DC. ${ }^{7}$ BIP Institute of Psychology Ltd., Israel. ${ }^{8}$ Nanyang Technological University, Singapore. ${ }^{9}$ Kaplaskjolsvegur, Reykjavik, Iceland. ${ }^{10}$ Koc University, Turkey. Jacobs University, Bremen, Germany. ${ }^{12}$ War saw School of Social Sciences and Humanities, Poland. ${ }^{13}$ University of Minho, Braga, Portugal. ${ }^{14}$ Chinese University of Hong Kong. ${ }^{15}$ Indian Institute of Management, India. ${ }^{16}$ Pontificia Universidad Catolica del Peru, ${ }^{17}$ University of Valencia, Spain. ${ }^{18} \mathrm{~J}$ ohannes Kepler University, Linz, Austria. ${ }^{19}$ Victoria University of Wellington, New Zealand. ${ }^{20}$ Hungarian Academy of Sciences, Budapest, Hungary. ${ }^{21}$ University of Athens, Greece. ${ }^{22}$ School of Psychological Science, La Trobe University, Bundoora, Victoria 3086, Australia. ${ }^{23}$ University of Melbourne, Australia. ${ }^{24}$ Sungkyunkwan University, Seoul, Korea. ${ }^{25}$ ESSEC Business School, Cedex, France. ${ }^{26}$ University of San Diego, San Diego, CA. ${ }^{27}$ Selangor, Malaysia. ${ }^{28} \mathrm{KU}$ Leuven, Belgium. ${ }^{29}$ University of Patras, Greece. ${ }^{30}$ Human Sciences Research Council, Pretoria, South Africa. ${ }^{31}$ Investigadora Colegio de la Fontera Norte, Tijuana, Baja California, México. ${ }^{32}$ Odessa National University, Ukraine. ${ }^{33}$ University of Tartu, Estonia. ${ }^{34}$ Norwegian School of Economics and Business Administration, Bergen, Norway. ${ }^{35}$ Universitat Koblenz-Landau, Landau, Germany. ${ }^{36}$ University of Sussex, Brighton, UK. ${ }^{37}$ University of Sindh, Hyderabad, Pakistan. ${ }^{38} 33$ Soonvijai 4, Bangkok 10310, Thailand. ${ }^{39}$ Gakushuin University, Tokyo, Japan. ${ }^{40}$ University of Groningen, Groningen, Netherlands. ${ }^{41}$ Indian Institute of Management, Ahmedabad, India. ${ }^{42}$ Victoria University of Wellington, New Zealand. ${ }^{43}$ University of Tokyo, Japan. 


\begin{abstract}
With data from 33 nations, we illustrate the differences between cultures that are tight (have many strong norms and a low tolerance of deviant behavior) versus loose (have weak social norms and a high tolerance of deviant behavior). Tightness-looseness is part of a complex, loosely integrated multilevel system that comprises distal ecological and historical threats (e.g., high population density, resource scarcity, a history of territorial conflict, and disease and environmental threats), broad versus narrow socialization in societal institutions (e.g., autocracy, media regulations), the strength of everyday recurring situations, and micro-level psychological affordances (e.g., prevention self-guides, high regulatory strength, need for structure). This research advances knowledge that can foster cross-cultural understanding in a world of increasing global interdependence and has implications for modeling cultural change.
\end{abstract}


How "other" cultures differ from one's own has piqued the curiosity of scholars and laypeople across the centuries. As long ago as 400 B.C.E., Herodotus documented a wide variety of cultural practices that he observed in his travels in The Histories (J). Only in the past few decades have scientists begun to move beyond descriptive accounts of cultural differences to empirically assess ways in which national cultures vary. We examine a neglected source of cultural variation that is dominating the geopolitical landscape and has the potential to be a major source of cultural conflict: the difference between nations that are "tight"-have strong norms and a low tolerance of deviant behavior and those that are "loose"-have weak norms and a high tolerance of deviant behavior.

Early anthropological research showed the promise of this distinction. In his study of 21 traditional societies, Pelto (2) documented wide variation in the expression of and adherence to social norms. The Hutterites, Hanno, and Lubara were among the tightest societies, with very strong norms and severe sanctions for norm violation, whereas the Kung Bushman, Cubeo, and the Skolt Lapps were among the loosest societies, with ambiguous norms and greater permissiveness for norm violation. Pelto speculated that these societies may have different ecologies, with tight societies having a higher population per square mile and a higher dependence on crops as compared to loose societies. Later research indeed showed that agricultural societies (e.g., the Temne of Sierra Leone), which require strong norms to foster the coordination necessary to grow crops for survival, had strict child-rearing practices and children who were high on conformity. Hunting and fishing societies (e.g., the Inuit) had lenient child-rearing practices and children who were low on conformity $(3,4)$.

Despite evidence of the importance of this contrast in traditional societies, there exists no insight into how tightness-looseness operates in modern nations. The goal of this research is to fill this void. Drawing on theorizing in cultural psychology $(5,6)$, we propose that tightness-looseness is part of a complex, loosely integrated system that involves processes across multiple levels of analysis (Fig. 1). We 
theorize that the strength of social norms and tolerance of deviant behavior-the core distinction between tight and loose cultures-is afforded by numerous distal ecological and human-made societal threats and societal institutions and practices. The strength of social norms and tolerance of deviant behavior is further reflected and promoted in the predominance of strong versus weak situations that are recurrent in everyday local worlds, and is reinforced through psychological processes that are attuned to situational requirements. We provide an empirical test that shows how ecological, historical, and institutional factors, along with everyday situations and psychological processes, together constitute cultural systems.

We predict that tightness-looseness is afforded by a broad array of ecological and human-made societal threats (or lack thereof) that nations have historically encountered (4, 7). Ecological and humanmade threats increase the need for strong norms and punishment of deviant behavior in the service of social coordination for survival whether it is to reduce chaos in nations that have high population density, deal with resource scarcity, coordinate in the face of natural disasters, defend against territorial threats, or contain the spread of disease. Nations facing these particular challenges are predicted to develop strong norms and have low tolerance of deviant behavior to enhance order and social coordination to effectively deal with such threats. Nations with few ecological and human-made threats, by contrast, have a much lower need for order and social coordination, affording weaker social norms and much more latitude (8).

The strength of social norms and tolerance of deviant behavior is also afforded by and reflected in prevailing institutions and practices. Institutions in tight nations have narrow socialization that restricts the range of permissible behavior, whereas institutions in loose nations encourage broad socialization that affords a wide range of permissible behavior (9). Relative to loose nations, tight nations are more likely to have autocratic governing systems that suppress dissent, to have media 
institutions (broadcast, paper, Internet) with restricted content and more laws and controls, and to have criminal justice systems with higher monitoring, more severe punishment (e.g., the death penalty), and greater deterrence and control of crime. Tight nations will also be more religious, thereby reinforcing adherence to moral conventions and rules that can facilitate social order and coordination (JO). Challenges to societal institutions (e.g., demonstrations, boycotts, strikes) will be much less common in tight nations than in loose ones. These institutions and practices simultaneously reflect and support the strength of norms and tolerance of deviance that exists in nations.

Tightness-looseness is manifested not only in distal ecological, historical, and institutional contexts but also in everyday situations in local worlds (e.g., at home, in restaurants, classrooms, public parks, libraries, the workplace) that individuals inhabit $(5,6)$. We theorize that tightness-looseness is reflected in the predominance of strong versus weak everyday situations $(11,12)$. Strong situations have a more restricted range of appropriate behavior, have high censuring potential, and leave little room for individual discretion. Weak situations place few external constraints on individuals, afford a wide range of behavioral options, and leave much room for individual discretion. Situational strength has been long discussed among psychologists, sociologists, and anthropologists (11-14) but has yet to be linked to cultural variation. Tight nations are expected to have a much higher degree of situational constraint which restricts the range of behavior deemed appropriate across everyday situations (e.g., classrooms, libraries, public parks, etc.). By contrast, loose nations are expected to have a much weaker situational structure, affording a much wider range of permissible behavior across everyday situations. The strength (or weakness) of everyday recurring situations within nations simultaneously reflects and supports the degree of order and social coordination in the larger cultural context.

We further theorize that there is a close connection between the strength (versus weakness) of everyday situations and the chronic psychological processes of individuals within nations. In this view, 
individuals' psychological processes become naturally attuned to, and supportive of, the situational demands in the cultural system (15). Individuals who are chronically exposed to stronger (versus weaker) situations in their everyday local worlds have the continued subjective experience that their behavioral options are limited, their actions are subject to evaluation, and there are potential punishments based on these evaluations. Accordingly, individuals in nations with high situational constraint will have self-guides that are more prevention-focused (16) and thus will be more cautious (concerned with avoiding mistakes) and dutiful (focused on behaving properly), and will have higher self-regulatory strength (higher impulse control) (17), a higher need for structure (18), and higher selfmonitoring ability $(19,20)$. Put simply, the higher (or lower) degree of social regulation that exists at the societal level is mirrored in the higher (or lower) amount of self-regulation at the individual level in tight and loose nations, respectively. Such psychological processes simultaneously reflect and support the strength of social norms and tolerance of deviance in the larger cultural context.

To provide a systematic analysis of tightness-looseness in modern societies, we gathered data from 6823 respondents across 33 nations (20). Sample characteristics are shown in Table 1 (21). In each nation, we surveyed individuals from a wide range of occupations as well as university students. Data on ecological and historical threats and societal institutions were collected from numerous established databases (20). When possible, historical data were included (e.g., population density in 1500, history of conflict 1918-2001, historical prevalence of pathogens).

Tightness-looseness (the overall strength of social norms and tolerance of deviance) was measured on a six-item Likert scale that assessed the degree to which social norms are pervasive, clearly defined, and reliably imposed within nations. Example scale items include "There are many social norms that people are supposed to abide by in this country," "In this country, if someone acts in an inappropriate way, others will strongly disapprove," and "People in this country almost always comply 
with social norms." The results show strong support for the reliability and validity of the measure (20). Ecological factor analyses and Procrustes factor analysis in all 33 nations illustrate that the scale exhibits factor validity and measurement equivalence. Analyses show that the strength of social norms and tolerance of deviance is a shared collective construct: There is high within-nation agreement in each nation $\left[r_{\text {within-group }}(M)=0.85\right]$, high between-nation variability $[F(32,6,774)=31.23, \mathrm{P}<0.000 \mathrm{I}$; intraclass correlation $(\mathrm{ICC})(\mathrm{I})=0.13]$, and high reliability of the tightness-looseness scale means [ICC $(2)=$ 0.97]. The scale has high convergent validity with expert ratings, unobtrusive measures, and survey data from representative samples; is able to adequately discriminate between cultural regions; and is distinct from other cultural dimensions (20) (tables SI and S2).

The degree of constraint across a wide range of everyday social situations was measured through adaptations to Price and Bouffard's established measure (20). Participants rated the appropriateness of 12 behaviors (i.e., argue, eat, laugh, curse/swear, kiss, cry, sing, talk, flirt, listen to music, read newspaper, bargain) across 15 situations (i.e., bank, doctor's office, job interview, library, funeral, classroom, restaurant, public park, bus, bedroom, city sidewalk, party, elevator, workplace, movies), resulting in a total of 180 behavior situation ratings (20). For a given situation, the mean appropriateness ratings across behaviors indicate the degree of situational constraint: Low values indicate that there are few behaviors considered appropriate in that situation, whereas high values indicate that a wide range of behaviors are considered appropriate in that situation. Country-level scores of situational constraint were derived by averaging scores across situations. Analyses illustrate that the situational constraint measure is a shared collective construct within nations (20): There is high within-nation agreement about the level of constraint in everyday situations in each nation $[r$ within$\operatorname{group}(M)=0.99]$, high between-nation variability in situational constraint $[F(32,6790)=92.9, P<0.0001$ $\operatorname{ICC}(1)=0.31$, and high reliability of the situational constraint means $[\operatorname{ICC}(2)=0.99]$. There is strong 
construct validity of the measure (20). Respondents in each nation also provided direct ratings regarding whether the 15 situations had clear rules for appropriate behavior, called for certain behaviors and not others, required people to monitor their behavior or "watch what they do," and allowed individuals to choose their behavior (reverse-coded), the average of which is highly correlated with the behaviorsituation ratings $(r=0.74, P<0.001)$. The correlation of the current situational constraint data in the United States with those reported by Price and Bouffard is $0.92(P<0.001)(20)$, which suggests that the degree of constraint across situations is generally stable across time.

Psychological processes (prevention focus, self-regulation strength, need for order, selfmonitoring) were assessed with well-validated measures (20). Procrustes factor analysis of all of the measures across the 33 nations all evidenced high equivalence and high degrees of cross-national variation (20).

To test our predictions, we first examine the relationships between tightness-looseness and ecological and historical institutions. Because many of these variables are associated with national wealth, we controlled for nations' GNP per capita to examine their unique relationships with tightnesslooseness. We next illustrate how tightness-looseness is related to the strength of everyday situations and examine the cross-level relationship between the strength of situations and numerous psychological processes with the use of hierarchical linear modeling. We provide a test of the overall model with multilevel structural equation analysis (20).

Table S3 illustrates that nations that have encountered ecological and historical threats have much stronger norms and lower tolerance of deviant behavior. Tight nations have higher population density in the year $1500(r=0.77, P=0.01)$, in the year 2000 in the nation $(r=0.31, P=0.10)$, and in the year 2000 in rural areas $(r=0.59 ; P=0.02)$, and also have a higher projected population increase $(r=$ $0.40, P=0.03)$. Tight nations have a dearth of natural resources, including a lower percentage of 
farmland $(r=-0.37, P=0.05)$, higher food deprivation $(r=0.52, P<0.0 \mathrm{I})$, lower food supply and production ( $r=-0.36, P=0.05$, and $-0.40, P=0.03$, respectively), lower protein and fat supply $(r s=-0.41$ and-0.46, $P_{s}=0.03$ and $\left.0.0 \mathrm{I}\right)$, less access to safe water $(r=-0.50, P=0.01)$, and lower air quality $(r=-$ $0.44, P=0.02)$, relative to loose nations. Tight nations face more disasters such as floods, tropical cyclones, and droughts $(r=0.47, P=0.01)$ and have had more territorial threats from their neighbors during the period 1918-2001 $(r=0.41, P=0.04)$. Historical prevalence of pathogens was higher in tight

\section{INSERT FIGURE 1 HERE}

nations $(r=0.36, P=0.05)$, as were the number of years of life lost to communicable diseases $(r=0.59$, $P<0.01)$, the prevalence of tuberculosis $(r=0.61, P<0.01)$, and infant and child mortality rates $(r s=0.42$, $P=0.02$, and $0.46, P=0.01$ ).

Tightness-looseness is reflected in societal institutions and practices (table S3). Tight nations are more likely to have autocratic rule that suppresses dissent $(r=0.47, P=0.01)$, less open media overall $(r=$ $-0.53, P<0.01)$, more laws and regulations and political pressures and controls for media $(r s=0.37$ to $\left.0.62, P_{s} \leq 0.05\right)$, and less access to and use of new communication technologies $(r=-0.38, P=0.04)$. Tight nations also have fewer political rights and civil liberties ( $r s=-0.50$ and-0.45, $\left.P_{s} \leq 0.01\right)$. Criminal justice institutions in tight nations are better able to maintain social control: There are more police per capita ( $r=0.31, P=0.12)$, stricter punishments (i.e., retention of the death penalty) $(r=0.60, P<0.01$ ), and lower murder rates and burglary rates $(r s=-0.45$ and $-0.47, P s<0.01)$ and overall volume of crime $(r=-$ $0.37, P=0.04)$. Tight nations are more religious, with more people attending religious services per week $(r=0.54, P<0.01)$ and believing in the importance of god in life $(r=0.37, P<0.05)(20)$. The percentage of people participating in collective actions (e.g., signing petitions, attending demonstrations) is much lower in tight nations $(r=-0.40, P=0.03)$, and more people report that they would never engage in such actions $(r=0.36, P=0.05)$ in comparison to loose nations Tightness-looseness is also related to the 
strength of everyday recurring situations within nations. As predicted, there is much higher situational constraint in tight versus loose nations $(r=0.55, P<0.01)(22)$. In other words, there is much higher constraint across everyday situations including the bank, public park, library, restaurant, bus, workplace, party, classroom, and the like in loose nations, and much lower constraint across such everyday situations in tight nations (20). Hierarchical linear modeling intercept-as-outcomes models showed that higher levels of situational constraint are significantly related to greater prevention self-guides [higher cautiousness: $Y_{01}=1.48,1(31)=7.54, P<0.01$; higher dutifulness: $\left.Y_{01}=1.11,1(31)=5.05, P<0.01\right]$, greater self-regulation strength [higher impulse control: $Y_{01}=1.18,1(31)=6.60, P<0.01$ ], higher needs for structure $\left[Y_{01}=2.67,1(31)=5.76, P<0.01\right]$, and higher self-monitoring $\left[Y_{01}=0.94,1(31)=3.69, P<\right.$ 0.01] (23). This suggests that societal members' psychological characteristics are attuned to and supportive of the degree of constraint versus latitude in the larger cultural context. Multilevel structural equation analyses that simultaneously tested the proposed relations in Fig. 1 illustrated very good fit to the data (20).

In all, the data illustrate that tightness-looseness, a critical aspect of modem societies that has been heretofore unexplored, is a part of a system of interrelated distal and proximal factors across

\section{INSERT TABLE 1 HERE}

multiple levels of analysis. In addition to explicating how tight and loose cultures vary in modern societies, this research has implications for understanding and modeling how tight and loose cultures are maintained and changed. Substantial top-down or bottom-up changes in any of the levels in the model may trigger a rippling effect to other levels, resulting in changes in tight or loose cultures.

As culture is fundamentally a system, causal inferences regarding the direction of the relationships need further examination, particularly given that they are likely reciprocal. Future research 
should also apply the basic principles of the current work to explore variation in tightness-looseness at other levels of analysis (e.g., regions). We also note that the samples in this study are not representative of each nation. However, the diverse backgrounds of the participants, high agreement among different subgroups, and correlations with other measures drawn from representative samples lend confidence to the generalizability of the results (20).

This research illuminates the multitude of differences that exist across tight and loose cultures. From either system's vantage point, the "other system" could appear to be dysfunctional, unjust, and fundamentally immoral, and such divergent beliefs could become the collective fuel for cultural conflicts. Indeed, as Herodotus (1) remarked centuries ago, "if one were to order all mankind to choose the best set of rules in the world, each group would, after due consideration, choose its own customs; each group regards its own as being the best by far" (p. 185). Such beliefs fail to recognize that tight and loose cultures may be, at least in part, functional in their own ecological and historical contexts. Understanding tight and loose cultures is critical for fostering cross-cultural coordination in a world of increasing global interdependence. 
Distal Ecological and Historical Factors and Societal Processes

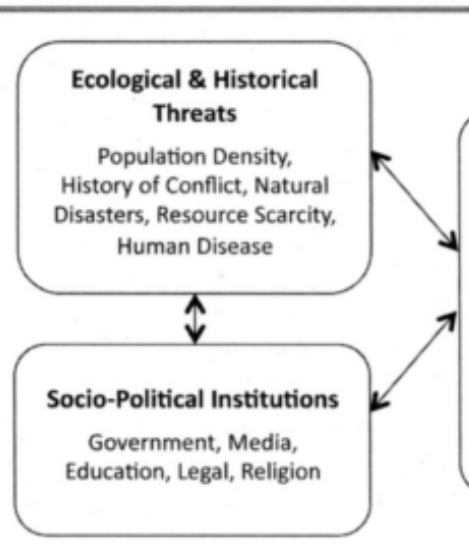

Fig. 1. A systems model of tightness-looseness.

Table 1. Sample characteristics of the 33 nations.

\begin{tabular}{|c|c|c|c|c|c|c|c|}
\hline Nation & Data collection site(s) & $\begin{array}{l}\text { Language } \\
\text { of survey }\end{array}$ & $\begin{array}{l}\text { Number of } \\
\text { participants }\end{array}$ & $\begin{array}{l}\text { Mean age } \\
( \pm S D)\end{array}$ & $\begin{array}{l}\text { Percentage } \\
\text { female }\end{array}$ & $\begin{array}{l}\text { Percentage } \\
\text { students }\end{array}$ & $\begin{array}{l}\text { Tightness } \\
\text { score }\end{array}$ \\
\hline Australia & Melbourne & English & 230 & $25.4 \pm 10.0$ & 69.1 & 63.9 & 4.4 \\
\hline Austria & $\operatorname{Linz}$ & German & 194 & $31.6 \pm 11.8$ & 51.5 & 41.8 & 6.8 \\
\hline Belgium & Leuven (Flanders region) & Dutch & 138 & $33.3 \pm 14.3$ & 73.2 & 50.7 & 5.6 \\
\hline Brazil & São Paulo & Portuguese & 196 & $27.5 \pm 9.4$ & 72.3 & 40.3 & 3.5 \\
\hline Estonia & Tartu & Estonian & 188 & $32.0 \pm 16.8$ & 86.6 & 52.1 & 2.6 \\
\hline France & Paris, Cergy & English & 111 & $25.2 \pm 4.1$ & 37.8 & 67.6 & 6.3 \\
\hline Germany (former East) & Chemnitz & German & 201 & $31.6 \pm 12.2$ & 66.7 & 49.3 & 7.5 \\
\hline Germany (former West) & Rhineland-Palatine/Frankfurt & German & 312 & $32.5 \pm 14.5$ & 63.8 & 51.6 & 6.5 \\
\hline Greece & Athens & Greek & 275 & $30.9 \pm 11.3$ & 56.7 & 45.1 & 3.9 \\
\hline Hong Kong & Hong Kong & Chinese & 197 & $27.3 \pm 11.7$ & 68.0 & 53.8 & 6.3 \\
\hline Hungary & Budapest, Szeged & Hungarian & 256 & $30.8 \pm 10.9$ & 42.2 & 48.0 & 2.9 \\
\hline Iceland & Reykjavík & Icelandic & 144 & $36.3 \pm 13.3$ & 67.4 & 41.7 & 6.4 \\
\hline India & $\begin{array}{l}\text { Ahmedabad, Bhubneswar, } \\
\text { Chandigarh, Coimbatore }\end{array}$ & Hindi & 222 & $27.8 \pm 9.6$ & 54.1 & 52.3 & 11.0 \\
\hline Israel & $\begin{array}{l}\text { Tel-Aviv, Ramat-Gan, } \\
\text { Jerusalem, Petach-Tikva }\end{array}$ & Hebrew & 194 & $30.2 \pm 10.7$ & 60.3 & 48.5 & 3.1 \\
\hline Italy & Padova & Italian & 217 & $29.6 \pm 10.3$ & 40.1 & 53.0 & 6.8 \\
\hline Japan & Tokyo, Osaka & Japanese & 246 & $33.2 \pm 14.9$ & 55.7 & 48.8 & 8.6 \\
\hline Malaysia & Bandar Baru Bangi & Malay & 202 & $29.5 \pm 9.1$ & 49.5 & 45.0 & 11.8 \\
\hline Mexico & Mexico City & Spanish & 221 & $27.7 \pm 11.6$ & 42.1 & 40.3 & 7.2 \\
\hline Netherlands & Groningen & Dutch & 207 & $29.8 \pm 11.9$ & 55.6 & 53.1 & 3.3 \\
\hline New Zealand & Wellington & English & 208 & $29.9 \pm 13.0$ & 64.4 & 61.1 & 3.9 \\
\hline Norway & Bergen & Norwegian & 252 & $31.8 \pm 11.0$ & 56.7 & 46.0 & 9.5 \\
\hline Pakistan & Hyderabad & Urdu & 190 & $30.0 \pm 9.8$ & 51.1 & 52.6 & 12.3 \\
\hline People's Republic of China & Beijing & Chinese & 235 & $29.4 \pm 11.5$ & 45.9 & 53.2 & 7.9 \\
\hline Poland & Warsaw & Polish & 210 & $28.5 \pm 12.4$ & 65.2 & 51.9 & 6.0 \\
\hline Portugal & Braga & Portuguese & 207 & $28.5 \pm 11.6$ & 54.6 & 58.0 & 7.8 \\
\hline Singapore & Singapore & English & 212 & $26.1 \pm 6.7$ & 59.0 & 49.1 & 10.4 \\
\hline South Korea & Seoul & Korean & 196 & $26.2 \pm 7.5$ & 61.2 & 73.5 & 10.0 \\
\hline Spain & Valencia & Spanish & 172 & $30.2 \pm 9.6$ & 66.9 & 40.1 & 5.4 \\
\hline Turkey & Istanbul & Turkish & 195 & $32.0 \pm 14.4$ & 53.3 & 45.6 & 9.2 \\
\hline Ukraine & Odessa & Ukrainian & 184 & $30.8 \pm 12.7$ & 56.5 & 44.6 & 1.6 \\
\hline United Kingdom & Brighton & English & 185 & $29.9 \pm 11.5$ & 67.0 & 51.4 & 6.9 \\
\hline United States & $\begin{array}{l}\text { Washington, DC; } \\
\text { Maryland; Virginia }\end{array}$ & English & 199 & $31.4 \pm 13.7$ & 60.3 & 48.2 & 5.1 \\
\hline Venezuela & Caracas & Spanish & 227 & $35.8 \pm 10.0$ & 60.4 & 1.3 & 3.7 \\
\hline Totals/means & & & 6823 & $30.1 \pm 11.3$ & 58.6 & 49.2 & 6.5 \\
\hline
\end{tabular}

Proximal/Contemporaneous Processes

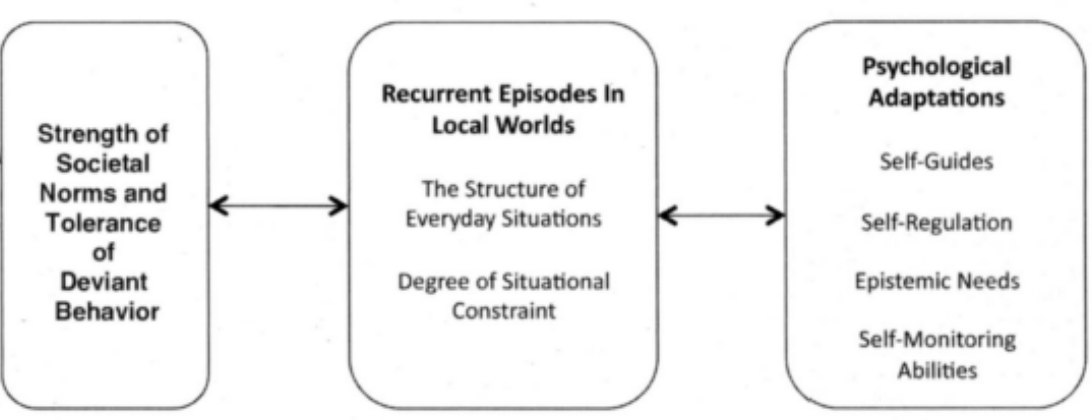




\section{References and Notes}

1. Herodotus, The Histories (Oxford, New York, 1998; R. Waterfield, Transl.).

2. P. J. Pelto, Trans Action 5, 37 (1968).

3. H. Barry III, I. L. Child, M. K. Bacon, Am. Anthropol. 62, SI (19S9).

4. J. W. Berry, Adv. Exp. Soc. Psychol. 12, 17.7 (1979).

5. S. Kitayama, Psychol. Bull. 128, 89 (2002).

6. A. Fiske, S. Kitayama, H. R. Markus, R. Nisbett, in The Handbook of Social Psychology, D. Gilbert, S. T. Fiske, G. Lindzey, Eds. (Oxford, New York, 1998), vol. 2, pp. 91S-981.

7. H. C. Triandis, The Analysis of Subjective Culture (Wiley, New York, 1972).

8. We acknowledge that these relationships are only probabilistic, as cultures can find equifinal solutions to ecological and historical threats (24). Moreover, the degree of tightness-looseness in societies can further reinforce the ecological context (6), making these relationships potentially reciprocal.

9. J. J. Arnett,]. Marriage Fam. 57, 617 (199S).

10. A. Norenzayan, A. F. Shariff, Science 322, S8 (2008).

11. W. Mischel, in Personality at the Crossroads, E. Magnusson, N. S. Endler, Eds. (Erlbaum, Hillsdale, NJ, 1977).

12. R. H. Price, D. L. Bouffar, J. Pers. Soc. Psychol. 30, S79 (1974).

13. E. D. Boldt, Can. J. Sociol. 3, 349 (1978). 
14. E. Goffman, Behavior in Public Places: Notes on the Social Organization of Gatherings (Greenwood, Westport, CT, 1963).

15. S. Kitayama, H. R. Markus, H. Matsumoto, V. Norasakkunkit, J. Pers. Soc. Psychol. 72, 124S (1997).

16. E.T. Higgins, Psychol. Rev. 94, 319 (1987).

17. R. F. Baumeister, T. F. Heatherton, Psychol. Inq. 7, 1 (1996).

18. S. L. Neuberg, J. T. Newsom, Personal. Processes Indiv. Diff. 65, 113 (1993).

19. M. Snyder, J. Pers. Soc. Psychol. 30, S26 (1974).

20. See supporting material on Science Online.

21. Most samples corresponded to nations; however, where subnational boundaries could be identified on the basis of historical circumstances, they were treated as separate samples (e.g., East and West Germany; Hong Kong and People's Republic of China).

22. For ease of interpretation, the situational constraint score was reversed such that high values are indicative of higher constraint.

23. We also ran these analyses with a split-sample approach (25) to eliminate single-source bias as an alternative explanation for our findings. Within each country we randomly assigned participants to one of two groups: One group provided the situational constraint scores and the other group provided the individual-difference scales. These hierarchical linear modeling results were the same as with the full sample.

24. D. Cohen, Psychol. Bull. 127, 4SI (2001).

2S. C. Ostroff, A.]. Kinicki, M. A. Clark,]. Appl. Psychol. 87, 3SS (2002). 
Acknowledgments: Supported by NSF grant 9910760 and U.S. Army Research Lab and Research Office grant W911NF-08-1-0144 (M.J.G.), Turkish Academy of Sciences (Z.A.), Polish Academy of Sciences (P.B.), Australian Research Council (Y.K.), and Estonian Ministry of Science (A.R.). We thank C. B. Bruss and R. Mohr for their help in preparing this manuscript. 